University of Wollongong

Research Online

Faculty of Engineering - Papers (Archive)

Faculty of Engineering and Information

Sciences

$12-12-2005$

\title{
Tsunami affected coastal soil disturbance and implications on reconstruction with special reference to low-cost dwellings and rail tracks
}

\author{
Buddhima Indraratna \\ University of Wollongong, indra@uow.edu.au \\ Mohamed A. Shahin \\ University of Wollongong, shahin@uow.edu.au \\ Cholachat Rujikiatkamjorn \\ University of Wollongong, cholacha@uow.edu.au \\ Hadi Khabbaz \\ University of Wollongong, khabbaz@uow.edu.au
}

Follow this and additional works at: https://ro.uow.edu.au/engpapers

Part of the Engineering Commons

https://ro.uow.edu.au/engpapers/196

\footnotetext{
Recommended Citation

Indraratna, Buddhima; Shahin, Mohamed A.; Rujikiatkamjorn, Cholachat; and Khabbaz, Hadi: Tsunami affected coastal soil disturbance and implications on reconstruction with special reference to low-cost dwellings and rail tracks 2005.

https://ro.uow.edu.au/engpapers/196
}

Research Online is the open access institutional repository for the University of Wollongong. For further information contact the UOW Library: research-pubs@uow.edu.au 
International Conference on Geotechnical Engineering for Disaster Mitigation \& Rehabilitation Chu, Phoon \& Yong (eds) (c) 2005 World Scientific Publishing Company ISBN 981-256-469-1

\title{
TSUNAMI AFFECTED COASTAL SOIL DISTURBANCE AND IMPLICATIONS ON RECONSTRUCTION WITH SPECIAL REFERENCE TO LOW-COST DWELLINGS AND RAIL TRACKS
}

\author{
BUDDHIMA INDRARATNA \\ Professor of Civil Engineering, University of Wollongong, Wollongong City, NSW 2522, \\ Australia \\ MOHAMED A. SHAHIN \\ Research Fellow, School of Civil, Mining and Environmental Engineering, University of \\ Wollongong, Wollongong City, NSW 2522, Australia \\ CHOLACHAT RUJIKIATKAMJORN \\ Research Associate, School of Civil, Mining and Environmental Engineering, University \\ of Wollongong, Wollongong City, NSW 2522, Australia \\ HADI KHABBAZ \\ Jeffery and Katauskas, Sydney, NSW, Australia
}

On 26 December 2004, the largest earthquake for more than 4 decades (magnitude 9.0) occurred between the Australian and Eurasian plates in the Indian Ocean (along the overly stressed Sunda trench) to the west of Aceh Province (Northern Sumatra). The quake triggered a series of waves that increased in height rapidly close to the shore (tsunami) spreading thousands of kilometers across the Bay of Bengal. In the Eastern and Southern coastal belt of Sri Lanka, the floodwaters reached almost $1 \mathrm{~km}$ inland, causing unprecedented damage to infrastructure and over 4000 fatalities. Widespread destruction included several kilometres of rail tracks, dislocating the track elements from the remolded surface soil. Near the beach town of Hikkaduwa, the ferocity of the waves was evident with the total destruction of tracks within $100 \mathrm{~m}$ from the shore, and overturning a crowded intercity train. Based on visual examination and CPT tests conducted several weeks later at the site of the train disaster, it was observed that the sandy topsoil was turbulently blended with transported marine sediments including organic fines. Under excessive hydraulic gradients, the geotechnical properties of surface soils up to a meter or more have been significantly altered. At some locations near the surface, the void ratios have almost doubled once the waves receded and the soil redeposited. In this paper, the relevant aspects of dwellings reconstruction and rail tracks on devastated coastal soils are elucidated. Guidelines for reconstructing robust costeffective foundations are discussed, based on the first author's own experience. Revised ballast grading and enhanced track conditions are considered, including the benefits of increasing track confining pressure and the essential need for soft formation stabilization. 
The use of geocomposites (i.e. bonded geogrid-geotextile layers) in achieving reduced track settlement, increased resilient modulus and decreased ballast degradation, is described.

\section{INTRODUCTION}

A tsunami travels from source area (usually earthquake epicenters) as a series of concentric waves. In the deep sea, these waves can travel at speeds of 500 to $800 \mathrm{~km} / \mathrm{h}$ from the epicenter, but approaching the shore, the waves decrease in speed to $20-30 \mathrm{~km} / \mathrm{h}$ while increasing the height as the kinetic energy transforms to potential energy. A wave that is only a meter in height in the deep ocean can grow to a few tens of meters at the shoreline (ITIC 2000). Destruction caused by tsunamis is the direct result of three factors: impact, inundation, and erosion. Both the incoming and receding waves can lead to a significant erosion of coastal sandy soils as well as inducing piping under excessive hydraulic gradients, undermining bridge piers, loss of foundation bearing capacity and confinement, apart from the obvious damage to structures upon wave impact.

The Boxing Day tsunami in December 2004 devastated several South and Southeast Asian countries including Indonesia (Northern Sumatra), Thailand (Phuket), Sri Lanka (Eastern and Southern Provinces), South India, Andaman and Maldives islands. The epicenter of this earthquake was measured as 9 on the Richter scale. As a consequence of the vertical 'throw' of the large discontinuity plane thus formed, high velocity ripples (more than $700 \mathrm{~km} / \mathrm{h}$ ) transformed to tsunami as the shallow depths (shorelines) were approached. While in most countries, the tidal waves directly impacted on the coastal belt, in Sri Lanka, while the eastern coast was destroyed by direct wave impact (waves up to $13 \mathrm{~m}$ ), its southern coast was severely damaged by the turbulent and rebound waves with considerable angular momentum with heights still reaching close to $10 \mathrm{~m}$. The damage caused by these turbulent waves were so catastrophic that hardly any houses and commercial buildings within a 100-150 m proximity to the shore were spared, and even the well built rail tracks and highways that have lasted for many decades were totally destroyed. The coastal stretch near the famous tourist beach town of Hikkaduwa was so badly hit. More than 1000 passengers lost their lives and many others injured, when the tsunami engulfed a crowded intercity train, derailing, toppling and submerging its carriages, making this train disaster the worst rail accident ever to be recorded. The lifting and piping of the formation soil beneath the track caused rapid demounting of the track, lifting it up with the tidal waters and displacing it several meters.

Site reconnaissance at the location of this train disaster was conducted under the guidance of the first author with the assistance provided by University of Moratuwa and Engineering Laboratory Services Ltd. The field observations indicated areas of significantly disturbed surface soils (at some locations up to $1 \mathrm{~m}$ ), now a heterogeneously mixed medium composed of the original topsoil blended with very fine beach sands, silts and organic sediments transported by the waves and construction materials (debris) turbulently mixed in situ. Once the waves receded, the 'piping' sands, eroded top soils, transported fine sediments (including organics) and debris have settled at a much higher porosity compared to the originally compacted sandy soil that have existed for hundreds of years. 
Sri Lanka has experienced a number of tsunamis given the past historical periods dating back over 2000 years, the last tsunami reported in June 1941 as a result of an earthquake of magnitude 8.1 near Andaman islands (Wattegama 2005). This paper will elucidate the need for rebuilding dwellings and rail tracks that are more resistant to future tsunamis as well as more resistant to possible earthquake tremors that Sri Lanka is now prone to. Given the recent history of earthquake epicenters and plate tectonics in the vicinity of the Sunda trench, Sri Lanka cannot be ruled out as earthquake free any longer. Especially where the coastal fine sands are prone to liquefaction, the roads and rail tracks require much more robust design implementation instead of conventional methods.

\section{PRELIMINARY SITE INVESTIGATIONS}

A trial open pit at an affected site indicated blended surface sands with no distinct layering, and clean relatively undisturbed sand was found at a depth exceeding $450 \mathrm{~mm}$. The particle size distributions (Figure 1) indicated only a more obvious well-graded nature of the sand closer to the surface, in the areas where the beach sand was known to be very uniform before the tsunami. The uniformity coefficient has changed form 1.6 to 4.6 in this particular location as a result of mixing. A standard cone penetrometer test (CPT) and a cone penetrometer test with pore pressure measurement (CPTU) were conducted to re-examine the soil profile up to $10 \mathrm{~m}$ deep, on 2 different locations near the train disaster site. Figures 2 and 3 illustrate measured parameters obtained from the CPT and CPTU, respectively. The friction ratios determined for the shallow depths (less than 1 $\mathrm{m}$ ) indicate metastable sands and/or mixed soils with increased sensitivity. It is also shown that soil layer up to $1 \mathrm{~m}$ was completely remolded by flooding. The surface compaction is essentially required to improve the ground condition. At greater depths exceeding $2 \mathrm{~m}$, the stable cohesionless sand deposits (unaffected by the tsunami) could be established from the CPT and CPTU profiles (Figures 2 and 3). The piezocone tests also indicated the increased pore pressures at various depths due to the presence of organic (peat) sediments and clayey sand/silt deposits that now carry increased moisture content due to the infiltration of water through the relatively pervious top sand layers (Figure 3 ). The hydrostatic pore pressure increases linearly and starts at the ground surface. The presence of peat layer is clearly identified by the suddenly increased friction ratio.

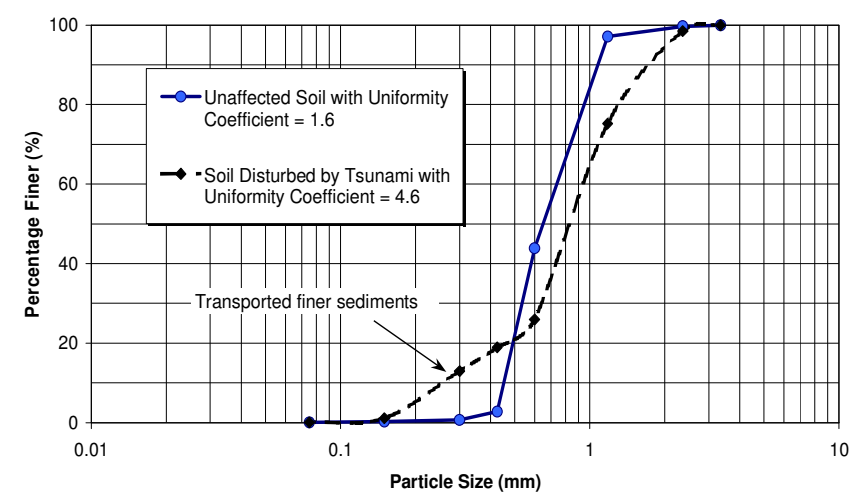

Figure 1. Particle size distribution curves of the tsunami affected and unaffected soils 


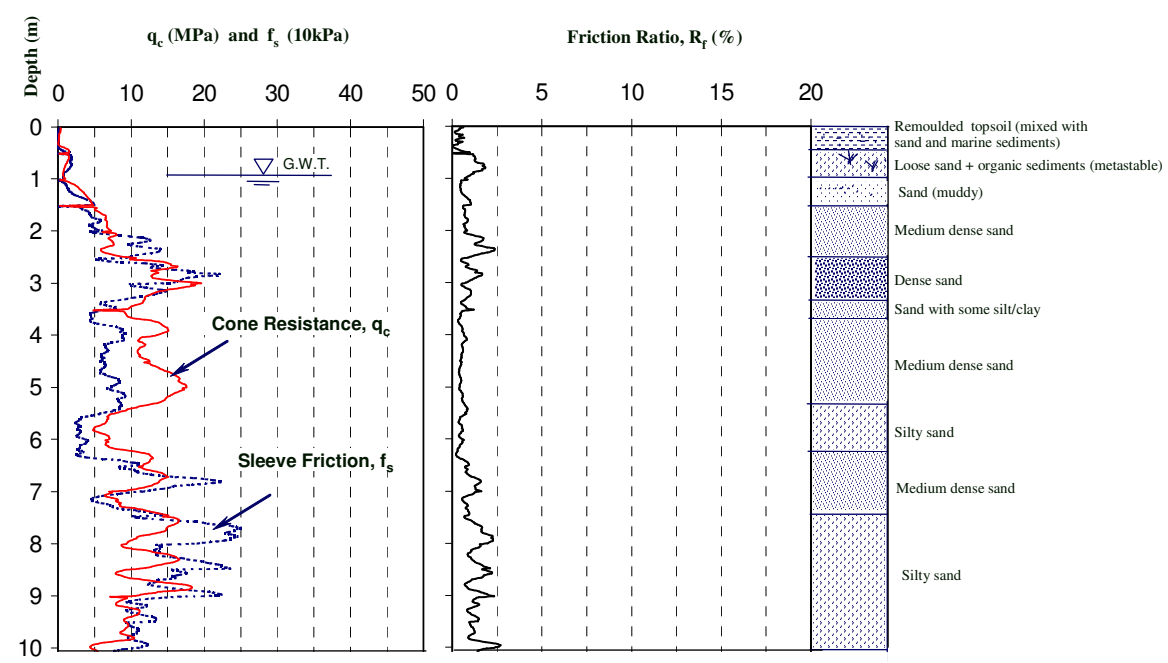

Figure 2. Cone penetration test (CPT) results of soil layers after tsunami occurrence

(Site 1)

The soil properties of a soil sample in tsunami-affected area showed a void ratio of about 0.7 at $600 \mathrm{~mm}$ depth, which is much higher than the initial pre-tsunami void ratio estimated to be less than 0.5 on the compacted surface. Assuming this range of void ratio and an associated saturated unit weight of about $21 \mathrm{kN} / \mathrm{m}^{3}$, the critical hydraulic gradient, $\mathrm{i}_{\mathrm{cr}}$, can be estimated from:

$\mathrm{i}_{\mathrm{cr}}=\left(\gamma_{\mathrm{s}} / \gamma_{\mathrm{w}}\right)-1 \approx 1.14$

where, $\gamma_{s}=$ unit weight of saturated soil and $\gamma_{w}=$ unit weight of water. The above value of $\mathrm{i}_{\mathrm{cr}}$ implies that a rapid flood with a height greater than $1 \mathrm{~m}$ may induce piping of the shallow surface soils to a substantial depth.

\section{RECONSTRUCTION GUIDELINES FOR HOUSING OF THE TSUNAMI AFFECTED AREAS}

Rehabilitation of tsunami victims is of paramount importance in future sustainable development plans in Sri Lanka. In this section, some guidelines for reconstructing lowcost dwellings in the affected coastal areas are proposed, in terms of: (a) locations and alignment of houses and (b) appropriate design of foundations.

\section{Locations and alignment of houses}

1. Dwellings should be constructed at a 'safe distance' of at least 100-200 m away from the beach depending on the area (e.g. presence or absence of mangroves, sand dunes, etc). The Eastern part of Sri Lanka is more prone to direct waves from the Indian ocean, whereas the Southern part of the island may receive rebound waves. 


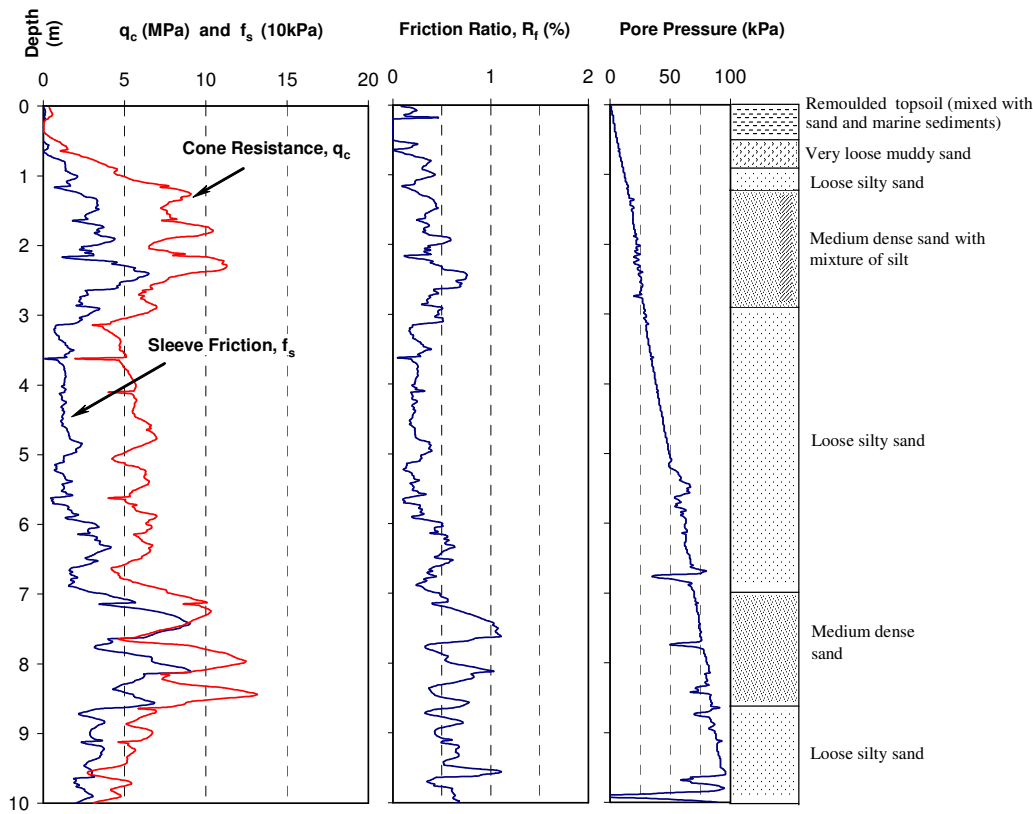

Figure 3. Cone penetration test with pore pressure (CPTU) results of soil layers after tsunami occurrence (Site 2)

2. Housing in areas behind densely grown palm trees (coconut and palmyrah) may be encouraged (Figure 4). These palms have fibrous root systems which facilitate the intake of groundwater from soil as deep as 2-3 meters. They provide high suction to hold together large volumes of fine soils that can otherwise be disturbed or remolded by extreme hydraulic gradients. Moreover, these strong roots provide excellent natural reinforcement for sandy coastal soils, increasing the apparent bearing capacity considerably.

3. For land at almost sea level, typical dwellings should be constructed on a raised earth platform in the order of 0.6-1 $\mathrm{m}$ in height, to provide protection against flooding and foundation scouring (Figure 5).

4. Dwellings may be constructed such that the strong masonry side faces the direction of waves (Figure 6). Mangroves must be encouraged as much as possible within the 'safe distance'. A group of houses should be arranged in a parallel pattern rather than random to create channels for the waves to pass through easily, with minimum damage.

\section{Recommended foundation design for housing units}

1. At sites affected by tsunami, proper soil investigations based on Cone Penetration Test and/or Standard Penetration Test should be carried out to determine the degraded soil properties and their distributions. The depth to sound (unaffected) soil 
layers needs to be estimated and the bearing capacity evaluated on the basis of shear strength.

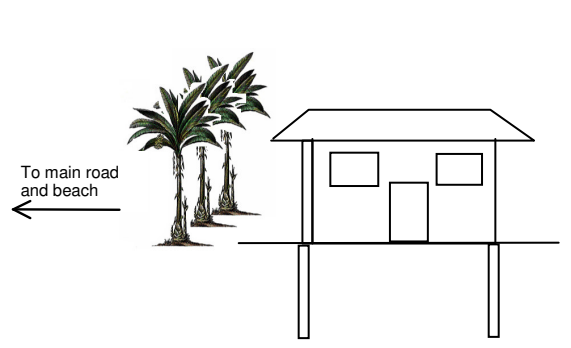

Figure 4. Protection from tree line

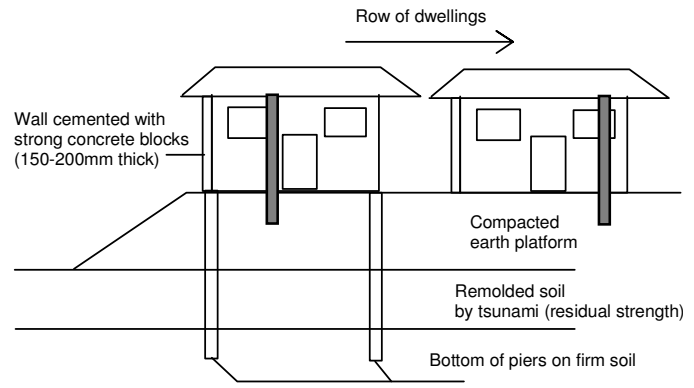

Figure 5. Housing construction on raised earth platform

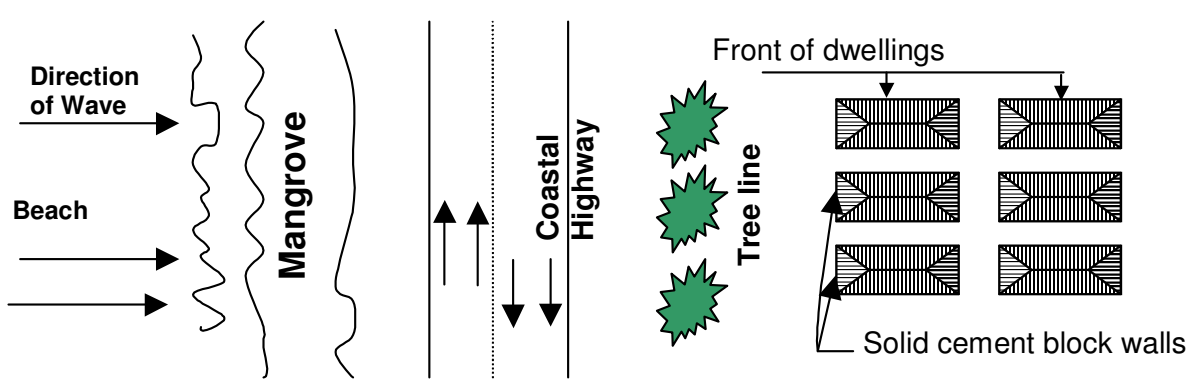

Figure 6. A preferable arrangement for a group of houses

2. Weakened soil conditions in some areas (1-2 $\mathrm{m}$ depth) should be stabilized by appropriate ground improvement techniques, as will be discussed later. Removal of transported soft marine sediments up to $200 \mathrm{~mm}$ from the soil surface is required, in some areas.

3. In order to provide strong strip footings, at least $250 \mathrm{~mm}$ wide trenches may be excavated up to $600 \mathrm{~mm}$ deep and the bottom of these trenches compacted to about $95 \%$ relative density. Subsequently, a $200-250 \mathrm{~mm}$ thick compacted gravel (size 7-10 $\mathrm{mm}$ ) layer may be placed at the bottom of the trench to provide a good drainage medium as well as to increase the bearing capacity (Figure 7). The gravel layer will rapidly dissipate excess pore pressure and also act as a damping layer in case of earthquake tremors. Concrete piers should be installed about every $3 \mathrm{~m}$ and at all corners of the dwellings as shown in Figure 8. These piers may be up to $1.5 \mathrm{~m}$ deep, resting on the medium dense sand, affected by tsunami.

4. Finally, the reinforced concrete footings should be placed above the compacted gravel layer to erect the houses (Figures 7 and 8). 


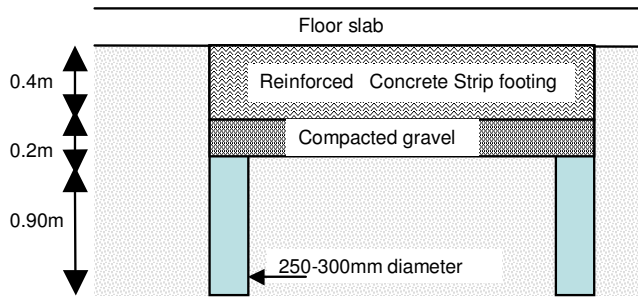

Figure 7. Foundation for soils affected by tsunami

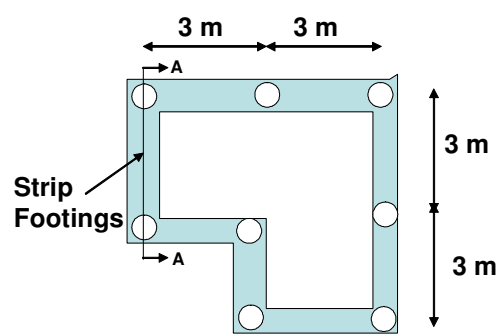

Figure 8. Typical plan view of foundation construction

\section{BALLAST AND TRACK MODIFICATION}

Ballast is the largest component of a rail track by weight and volume. While ballast is expected to be low-cost and in adequate supply, it also has to be capable of providing the engineering requirements of the rail track. The main functions of ballast are: distributing of loads received from the sleepers, damping of dynamic loads, producing lateral resistance and providing rapid drainage. Supplying high quality fresh ballast for reconstruction of rail track for entire region affected by tsunami is costly and time consuming. Therefore, the existing ballast of the damaged tracks can be reused, except for some areas that the track substructure has been totally washed out by the waves. Obviously, old ballast should be totally removed, cleaned, sieved and recompacted. Recycling of the in place ballast not only reduces the cost of track rehabilitation, but also contributes to waste reduction and decreases the need for extensive quarrying and environmental degradation. However, recycled ballast has lower internal friction angle due to attrition and reduced angularity, hence, exhibiting higher settlement and lateral deformation compared to those of fresh ballast upon cyclic loading. Research at University of Wollongong indicated that inclusion of geosynthetics improves the geotechnical properties of recycled ballast, as discussed later.

\section{Effect of particle size distribution}

The gradation of ballast is a prime consideration for track performance. To evaluate the effects of particle size distribution on deformation and degradation behavior of ballast, large-scale cyclic triaxial tests were conducted on four different distributions of latite basalt at University of Wollongong. Details of the testing apparatus can be found in Indraratna et al. (2003). The gradation and void ratio characteristics of the test specimens are shown in Figure 9. Samples were subjected to an effective confining pressure of approximately $45 \mathrm{kPa}$, and cyclic loading having a maximum deviator stress of $300 \mathrm{kPa}$ was applied on the ballast specimens at a frequency of $20 \mathrm{~Hz}$. Figure 10 shows the effect of grain size distribution on the axial and volumetric strains of ballast under cyclic loading. The tests results reveal that most uniform to moderately uniform samples give higher axial and volumetric strains. This is attributed to the looser states of the specimens prior to cyclic loading. In contrast, gap-graded and moderately graded distributions provided denser packing with a higher co-ordination number (increased surface contact). Therefore, these gradations provided a higher shear strength as well as reduced settlement. 
In terms of deformation and resistance to particle breakage (Figure 11), the test results indicate that moderately graded ballast is far superior to uniform gradations, which is now acknowledged in the current ballast specifications of some countries including Australia. The test results also indicate that moderately graded ballast is still porous enough to maintain sufficient track drainage. Based on these findings, Indraratna et al. (2004) recommended a ballast gradation with a uniformity coefficient exceeding 2.2 , but not more than 2.6, in comparison to very uniform (conventional) gradings with $\mathrm{C}_{\mathrm{u}}=1.4-1.5$. This recommended gradation, which is relatively more well-graded than the current Australian Standards (A S 2758.7 1996) is presented in Figure 12.

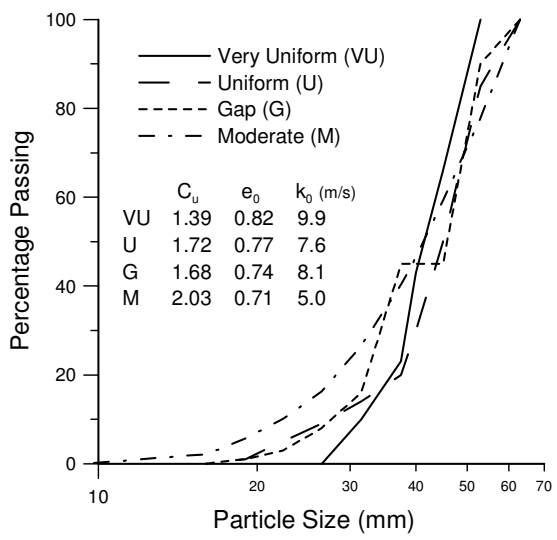

Figure 9. Particle size distributions used in the triaxial tests (Indraratna et al. 2004)

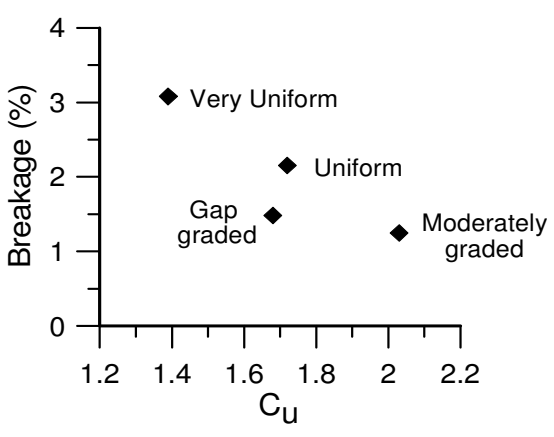

Figure 11. Effect of grading on particle breakage (Indraratna et al. 2004)

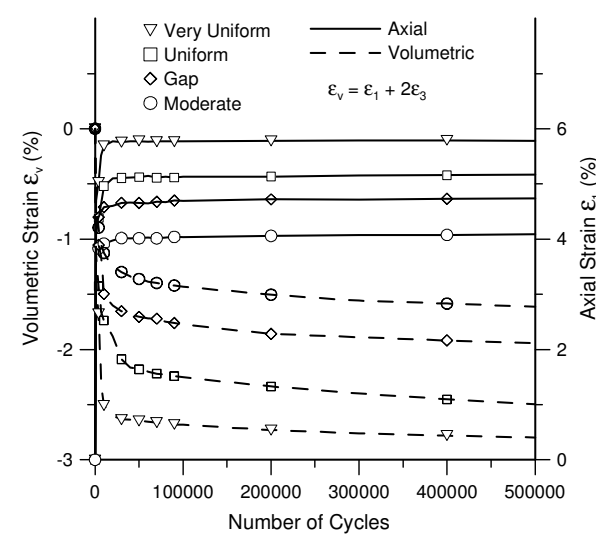

Figure 10. Axial and volumetric strain response of different distributions under cyclic loading (Indraratna et al. 2004)

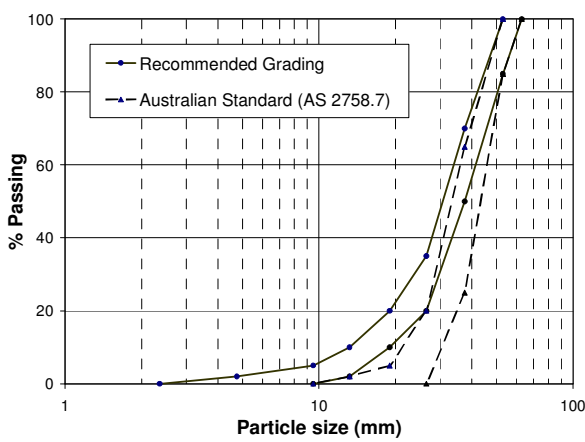

Figure 12. Recommended railway ballast grading in comparison with the current Australian Standard (Indraratna et al. 2004)

\section{Effect of confining pressure}

The role of confining pressure on ballast performance under cyclic loading has been investigated by Indraratna et al. (2005b). Figure 13 illustrates the effect of confining 
pressure $\left(\sigma_{3}{ }^{\prime}\right)$ on the axial and volumetric strains of ballast achieved at the end of 500,000 cycles for a maximum deviator stress of $500 \mathrm{kPa}$. As expected, the axial strains decreased with the increasing confining pressure. Ballast specimens exhibited dilation at small confining pressure $\left(\sigma_{3}{ }^{\prime}<30\right)$, but became progressively more compressive as the confining pressure increased from 30 to $240 \mathrm{kPa}$. The effect of confining pressure on particle degradation is shown in Figure 14. It was found that there is an optimum confining pressure $(30-75 \mathrm{kPa})$ in which the amount of ballast breakage was reduced to its minimum value. Some measures for increasing track confinement include: reducing sleeper spacing, increasing height of shoulder ballast, inclusion of a geosynthetic layer at the ballast-subballast layer interface, widening the sleepers at both ends (Figure 15), and using intermittent lateral restraints at various parts of the track (Figure 16).

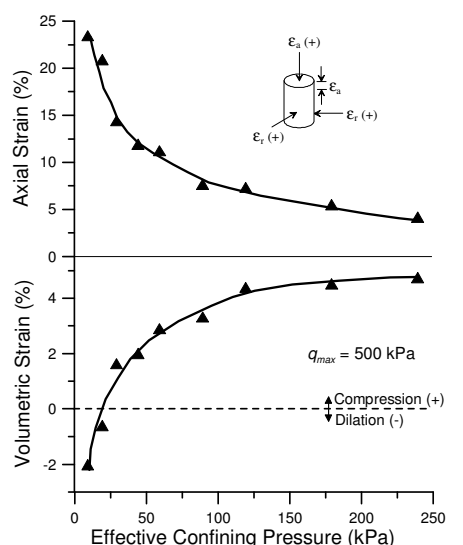

Figure 13. Variation of axial and volumetric strains with confining pressure (Indraratna et al. 2005b)

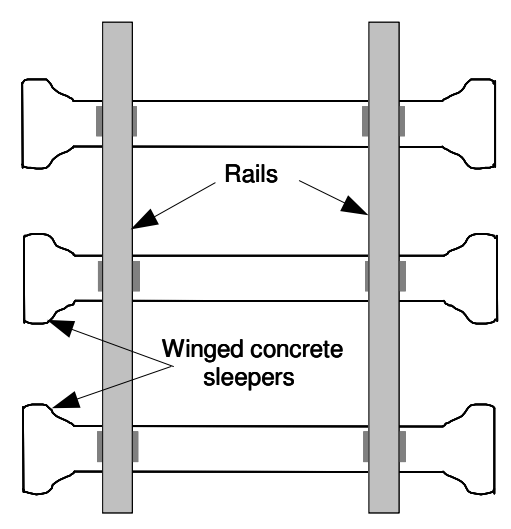

Figure 15. Sleepers with enlarged ends to Increase the confining pressures

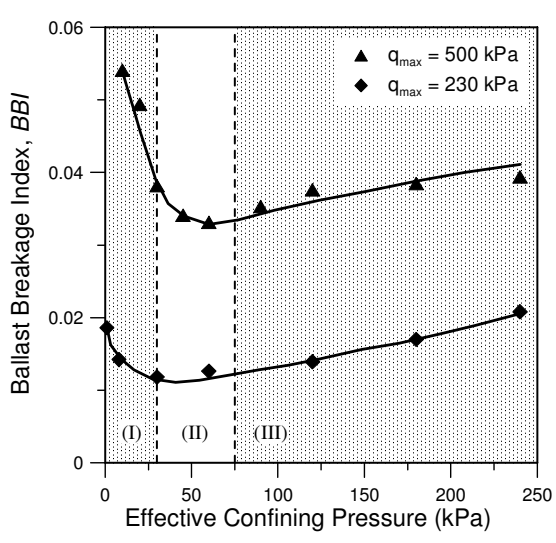

Figure 14. Effect of confining pressure on particle degradation (Indraratna et al. 2005b)

Intermittent lateral restraints

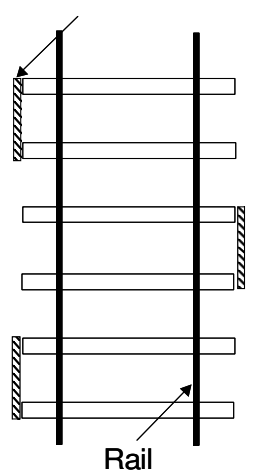

Lateral restraints

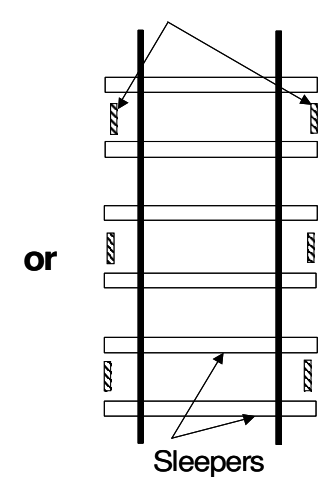

Figure 16. Increasing confining pressure using intermittent lateral restraints 


\section{Improvement of recycled ballast using geosynthetics}

The deformation and degradation behavior of fresh and recycled ballast was investigated in a large triaxial chamber (Figures 17 and 18) simulating a small track section. This large-scale prismoidal triaxial rig of $800 \mathrm{~mm}$ length, $600 \mathrm{~mm}$ width and $600 \mathrm{~mm}$ height was designed and installed at the University of Wollongong to model the cyclic loading response of ballasted tracks. By allowing the lateral strain of ballast upon loading, the triaxial rig with unrestrained sides provides a reliable facility for physical modeling of ballast. details of the large-scale rig can be found in Indraratna et al. (2003). The stabilization aspects of recycled ballast using various types of geosynthetics were also studied in these model tests. The effectiveness of various geosynthetics in stabilizing recycled ballast was investigated through laboratory model test results. Three types of geosynthetics were used including woven geotextiles, geogrids and geocomposites (bonded geogrids and non-woven geotextiles). The tests were conducted in both dry and wet conditions to study the effects of saturation. The testing procedures together with complete findings and discussions have been reported by Indraratna et al. (2004). Only selected results illustrating the effects of inclusion of geocomposites on ballast settlement and breakage are given in this paper.

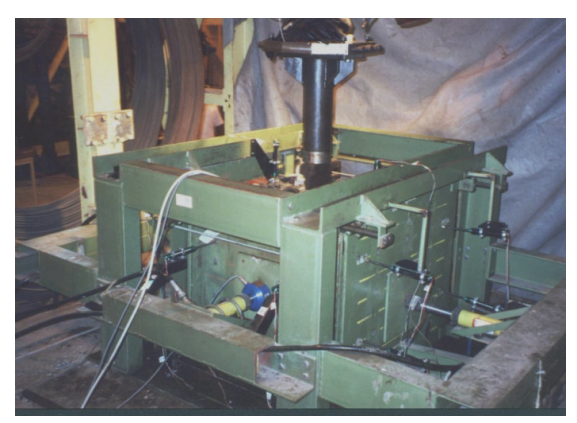

Figure 17. Large-scale prismoidal triaxial equipment built at the University of Wollongong

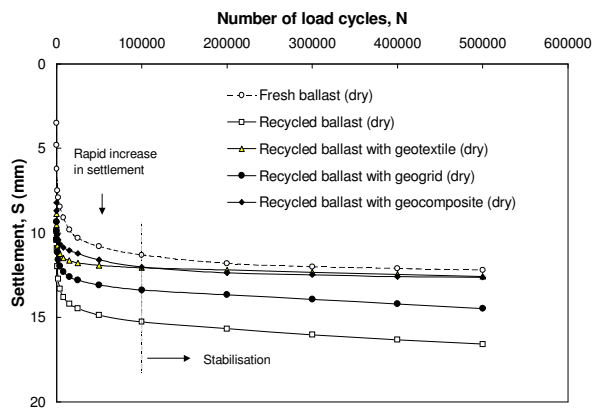

Figure 19. Settlement of dry fresh and recycled ballast with and without geosynthetics (Indraratna et al. 2004)

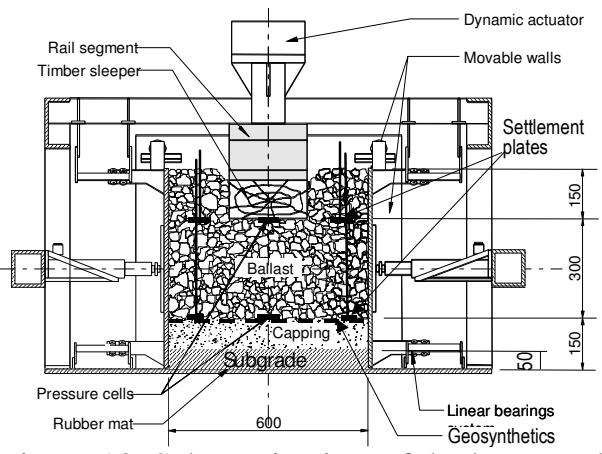

Figure 18. Schematic view of the large-scale prismoidal triaxial apparatus (Indraratna and Salim 2003)

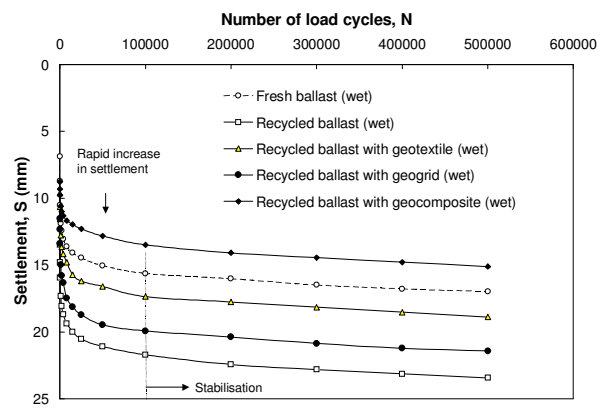

Figure 20. Settlement of wet fresh and recycled ballast with and without geosynthetics (Indraratna et al. 2004) 
Figures 19 and 20 show the settlement of fresh ballast without any reinforcement and recycled ballast with and without the inclusion of geosynthetics in dry and wet status, respectively. As expected, dry fresh ballast gives the least settlement. It is believed that the higher angularity of fresh ballast contributes to better particle interlock and therefore, causes less settlement. The test results reveal that wet recycled ballast (without any geosynthetic inclusion) generates significant settlement, because, water acts as a lubricant thereby reducing the frictional resistance and promoting particle slippage. Although geogrids and woven geotextiles decrease the settlement of recycled ballast considerably, the geocomposite (geogrid bonded with non-woven geotextiles) stabilizes recycled ballast remarkably well. As described by Rowe and Jones (2000), geocomposites can provide reinforcement to the ballast layer, as well as filtration and separation functions simultaneously. The combination of reinforcement by the geogrid and the filtration and separation functions provided by the non-woven geotextile component (of the geocomposite) reduces the lateral spreading and fouling of ballast, especially in wet conditions. The non-woven geotextile also prevents the fines moving up from the capping and subgrade layers, thus keeps the recycled ballast relatively clean.

To quantify ballast breakage based on Marsal's method (1967), each ballast specimen was sieved before and after testing, and the changes in percentage retained on each sieve size were recorded. The breakage index values of recycled ballast stabilized with geocomposites in dry and wet conditions were almost the same as fresh ballast (without geocomposites), and approximately $50 \%$ lower than those of recycled ballast without geosynthetics. This indicates clearly the benefits of using geosynthetics in the reduction of recycled ballast breakage in both dry and saturated conditions.

\section{SUBBALLAST LAYER}

Subballast is the layer of aggregates placed between the ballast layer and the subgrade. This is usually comprised of well-graded crushed rock or a sand/gravel mixture. The subballast layer should be designed to prevent the penetration of coarse ballast grains into the subgrade, and the upward migration of subgrade fines (formation soil) into the ballast layer. Therefore, subballast acts as a filter and a separating layer in the track substructure, which transmits and distributes stress from the ballast layer down to the subgrade over a wider area. It also acts as a drainage medium to dissipate cyclic pore water pressures developed by the passage of trains.

Using geotextiles in conjunction with a sand-capping layer is highly recommended for track subballast. The sand filter in this case prevents the migration of fine soil upwards, and the geotextile acts as a separator between the sand and ballast. Raymond (1986) recommended the non-woven needle punched geotextiles in preference to woven geotextiles, because the woven geotextile is unable to dissipate excess pore pressures quickly enough. This is particularly important in the case of freight trains that are both very heavy and very long.

\section{FORMATION SOIL MODIFICATION}

In many tsunami-affected areas in Southern Sri Lanka, the total rail track structure has to be removed before carrying out any reconstruction. Therefore, the subgrade condition should be carefully examined and appropriate measures have to be taken to improve the 
formation soil performance. One of the most important steps at the preliminary stage was identifying and classifying the subgrade soils. Although limited subsurface exploration has been conducted at the site (Indraratna et al. 2005a), no rail rehabilitation mission will be completed without reanalyzing the post-tsunami soils strength and densities along the coastal rail track and comparing this data with the pre-tsunami soil profiles and data, past geological maps and geotechnical reports. In general, two types of subgrade: (a) loose fine sand and (b) soft silty or clayey sediments need special consideration, as they are highly susceptible to failure under cyclic loading, including excessive plastic deformation and piping. Some differential settlement would be inevitable in some parts of the track that required urgent reconstruction for passenger transport without optimum soil improvement, but of course at a reduced train speed. For stabilizing the formation soils, a variety of options of ground improvement are available in Sri Lanka. Some selected key means of subgrade enhancement are discussed in this section.

\section{Loose sandy subgrade}

The preliminary site reconnaissance (Indraratna et al. 2005a) indicated that the disturbed top layer of the soil includes mixed soils such as loose sand with marine sediments (including dark brown to black organics). Densification of loose granular soils, heterogeneous soils and liquefiable soils can be achieved by surface compaction. The purpose of densification is to increase the relative density and the internal friction angle of the soil (shear strength), thereby reducing the post-construction settlement as well as increasing the bearing capacity. The surface vibratory or pneumatic compaction is regarded as the simplest and the cheapest method for densification of loose, saturated and cohesionless remolded soils in the tsunami affected areas. This method reduces the void volume of remolded soil by forcing the soil particles into a tighter state using dynamic forces. In the field, the soil up to $1 \mathrm{~m}$ deep can be compacted using rolling and kneading, of impact vibrating and ramming.

Grouting technology and chemical stabilization can also be used as alternatives to compaction to retard water seepage and to increase the shear strength of loose sand formations. For preventing formation collapse during significant earthquakes, deep mixing method may be employed to increase the liquefaction resistance of loose sediments beneath rail track and improve its stability.

\section{Clay subgrade}

In the region of the site of soil exploration, no thick layers of soft clays were found (up to 12-15 m depth), but clayey sands and organic sediments will still show significant compressibility. However, many coastal regions of Southeast Asia contain soft clays (estuarine or marine), which have poor geotechnical properties such as low bearing capacity and high compressibility. In the City of Colombo itself and to the south of Colombo towards the Southern Province that was devastated by the tsunami, compressible clays and peaty soils are often encountered, and some of these areas only just escaped the wrath of the tsunami. If these areas had been flooded, the subsequent settlement of buildings may have been substantial. Transport infrastructure including rail tracks are affected by the settlement and lateral movement of soft formation soils, in the absence of appropriate ground improvement prior to track reconstruction. In Sri Lanka, the improvement of clayey soft soils also requires equal attention as much as the loose sandy deposits in the Southern and Eastern provinces. This is because, towards the City 
of Colombo not only the coastal population increases, hence the need for taller buildings, but also the extent and the frequency of soft clays and peaty soils increase. Cost effective techniques for ground improvement are now employed for compressible formation soils in Sri Lanka. Some popular methods include: stabilization by chemical admixtures; geosynthetic reinforcement; and preloading and the use of prefabricated vertical drains.

\section{CONCLUSIONS}

Sri Lanka, among several other countries, was devastated by the Indian Ocean tsunami, which occurred on 26th December 2004. In this paper, the recommended procedures and suggestions that can be adopted for reconstruction of dwellings (including housing locations and design of foundations), and rail track substructures in the affected costal soils have been explained. The approaches recommended are cost-effective and not time consuming.

Based on the preliminary site investigation conducted by the first author, reconstruction of the affected areas requires reducing the soil void ratio to at least 0.45 to achieve an adequately stiff surface layer prior to the reconstruction process. Reconstructing low-cost dwellings in the affected coastal areas requires the following guidelines. Dwellings should be constructed at a safe distance of at least 100-200 m away from the beach in such away that the strong masonry side faces the direction of waves. Dwellings should also be constructed on a raised earth platform in the order of 0.6-1 $\mathrm{m}$ in height. Housing in areas behind densely grown palm trees is encouraging.

To accelerate rail track rehabilitation, selected waste ballast in tsunami-affected areas, when properly cleaned and stabilized with geosynthetics can be reused as load bearing materials. The use of composite geosynthetics at the bottom of the recycled ballast layer is highly desirable due to the heterogeneously mixed soils along the track. Geocomposites also decrease track lateral movement, ballast degradation and subgrade pumping.

It is illustrated that the gradation of ballast plays a significant role in the strength, deformation, degradation, stability and drainage of tracks. Well-graded ballast gives denser packing, better frictional interlock and hence, lower settlement. On the other hand, almost all ballast specifications demand uniform gradation for free draining. However, the uniformly graded ballast gives higher settlement and also more vulnerable to breakage than well-graded ballast. Test results indicate that the use of slightly broader graded ballast than the current Australian Standard gives considerably lower settlement and decreases the extent of breakage while not affecting drainage significantly. It is recommended that the rail tracks in Sri Lanka adopt a less uniform ballast gradation based on these findings. Another factor that affects the performance of ballast is the track confining pressure. Findings based on large scale triaxial testing indicate that a small increase in confining pressure $\left(\sigma_{3}{ }^{\prime}=30-75 \mathrm{kPa}\right)$ improves the track stability with less ballast degradation.

\section{ACKNOWLEDGEMENTS}

The contents of this paper are mainly taken from the first author's keynote paper at the International Symposium on Tsunami Reconstruction with Geosynthetics held in Bangkok, Thailand. The authors express their sincere gratitude to Cooperative Research Center for Railway Engineering and Technologies (Rail-CRC), RailCorp of NSW and 
related geosynthetics companies in Australia for their support and cooperation. Support provided by the Minister of Science and Technology of Sri Lanka is greatly acknowledged. The authors also express their special thanks to Dr Wadud Salim (RailCorp of NSW) and Ms Joanne Lackenby (PhD student at UoW) for their assistance and contribution.

\section{REFERENCES}

Australian Standards 2758.7 (1996). "Aggregates and rock for engineering purposes", Part 7: Railway Ballast.

Indraratna, B., Khabbaz, H., Puswewala, A. and Bandrara, W. (2005a). "Effects of tsunami on coastal ground conditions and appropriate measures for rail track rehabilitation", International Symposium on Tsunami Reconstruction with Geosynthetics - Protection, Mitigation and Rehabilitation of Coastal and Waterway Erosion Control, Bangkok, Thailand.

Indraratna, B., Khabbaz, H., Salim, W. and Christie, D. (2003). "Geotechnical characteristics of railway ballast and the role of geosynthetics in minimizing ballast degradation and track deformation", RAILTECH 2003 - Railway Technology in the New Millennium, Kuala Lumpur, Malaysia, 3.1-3.22.

Indraratna, B., Khabbaz, H., Salim, W., Lackenby, J. and Christie, D. (2004). "Ballast characteristics and the effects of geosynthetics on rail track deformation", International Conference on Geosynthetics and Geoenvironmental Engineering, ICGGE, Bombay, India, 3-12.

Indraratna, B., Lackenby, J. and Christie, D. (2005b). "Effect of confining pressure on the degradation of ballast under cyclic loading", Geotechnique, Vol. 55, No. 4, 325328.

Indraratna, B. and Salim, W. (2003). "Deformation and degradation mechanics of recycled ballast stabilized with geosynthetics", Soils and Foundations, Vol. 43, No. $4,35-46$.

ITIC (2000). "Tsunami classification and glossary", Intergovernmental Oceanographic Commission of UNESCO, Hawaii, 1-20.

Marsal, R.J. (1967). "Large scale testing of rockfill materials", Journal of Soil Mechanics and Foundation Engineering, Vol. ASCE, 93, No. SM2, 27-43.

Raymond, G.P. (1986). "Performance assessment of a railway turnout geotextile", Canadian Geotechnical Journal, Vol. 23, No. 4, 472-480.

Rowe, P.K. and Jones, C.J.F.P. (2000). "Geosynthetics: innovative materials and rational design", Proceedings, GEOENG 2000, Melbourne, Australia, Vol. 1, 11241156.

Wattegama, C. (2005). "The seven tsunamis that hit the isle of Sri Lanka", Engineering News, Institution of Engineers Sri Lanka, Vol. 40, No. 3, 6-7. 